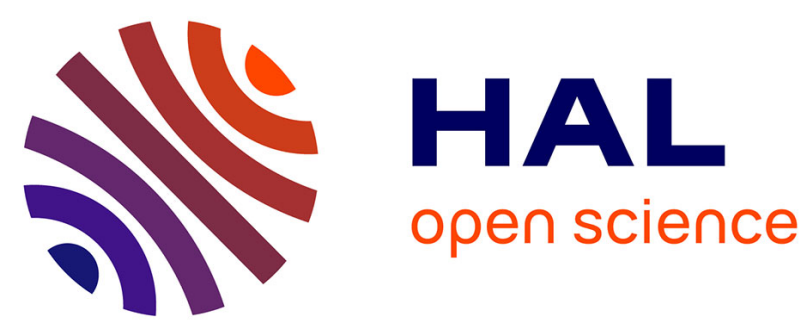

\title{
Constitutive mosaic aneuploidy is a unique genetic feature widespread in the Leishmania genus
}

Laurence Lachaud, Nathalie Bourgeois, Nada Kuk, Christelle Morelle, Lucien Crobu, Gilles Merlin, Patrick Bastien, Michel Pagès, Yvon Sterkers

\section{- To cite this version:}

Laurence Lachaud, Nathalie Bourgeois, Nada Kuk, Christelle Morelle, Lucien Crobu, et al.. Constitutive mosaic aneuploidy is a unique genetic feature widespread in the Leishmania genus. Microbes and Infection, 2014, 16 (1), pp.61-66. 10.1016/j.micinf.2013.09.005 . hal-02496197

\section{HAL Id: hal-02496197 \\ https://hal.umontpellier.fr/hal-02496197}

Submitted on 3 Mar 2020

HAL is a multi-disciplinary open access archive for the deposit and dissemination of scientific research documents, whether they are published or not. The documents may come from teaching and research institutions in France or abroad, or from public or private research centers.
L'archive ouverte pluridisciplinaire HAL, est destinée au dépôt et à la diffusion de documents scientifiques de niveau recherche, publiés ou non, émanant des établissements d'enseignement et de recherche français ou étrangers, des laboratoires publics ou privés.

\section{(ㅇ)(1) $\$$}

Distributed under a Creative Commons Attribution - NonCommercial - NoDerivatives| 4.0 


\section{Constitutive mosaic aneuploidy: a unique genetic feature widespread in the}

\section{Leishmania genus}

Laurence Lachaud $^{\mathrm{a}, \mathrm{b}^{*}}$, Nathalie Bourgeois ${ }^{\mathrm{a}, \mathrm{b}, \mathrm{c}^{*}}$, Nada Kuk $^{\mathrm{a}}$, Christelle Morelle ${ }^{\mathrm{a}, \mathrm{b}, \mathrm{c}}$, Lucien Crobu ${ }^{\mathrm{b}}$, Gilles Merlin $^{\mathrm{b}}$, Patrick Bastien ${ }^{\mathrm{a}, \mathrm{b}, \mathrm{c}}$, Michel Pagès ${ }^{\mathrm{b}}$ and Yvon Sterkers ${ }^{\mathrm{a}, \mathrm{b}, \mathrm{c}, \#}$

${ }^{\mathrm{a}}$ University Montpellier 1, Faculty of Medicine, Laboratory of Parasitology-Mycology, ${ }^{\mathrm{b}} \mathrm{CNRS}$ 5290 - IRD 224 - University Montpellier 1\&2 (UMR "MiVEGEC"), ${ }^{c}$ Centre Hospitalier Universitaire (University Hospital Centre), Montpellier, France, * these two authors equally contributed to the work

\# To whom correspondence should be addressed. Postal address : Laboratoire de ParasitologieMycologie, CHRU de Montpellier, 39, avenue Charles Flahault, 34295 Montpellier cedex 5, France. E-mail: yvon.sterkers@umontpHobHfr, genpara@univ-montp1.fr

This manuscript has been published, please cite: Constitutive mosaic aneuploidy is a unique genetic feature widespread in the Leishmania genus. Lachaud L, Bourgeois N, Kuk N, Morelle C, Crobu L, Merlin G, Bastien P, Pagès M, Sterkers Y. Microbes Infect. 2014 Jan;16(1):61-6. doi: 10.1016/j.micinf.2013.09.005. Epub 2013 Oct 8. PMID: 24120456 


\begin{abstract}
Using fluorescence in situ hybridization, we determined the ploidy of four species of Leishmania: L. infantum, L. donovani, L.tropica and L. amazonensis. We found that each cell in a strain possesses a combination of mono-, di- and trisomies for all chromosomes; ploidy patterns were different among all strains/species. These results extend those we previously described in L. major, demonstrating that mosaic aneuploidy is a genetic feature widespread to the Leishmania genus. In addition to the genetic consequences induced by this mosaicism, the apparent absence of alternation between haploid/diploid stages questions the modality of genetic exchange in Leishmania sp.
\end{abstract}

Keywords: ploidy; Leishmania; genome; chromosome; aneuploidy; mosaicism; genetic exchange 


\section{Introduction}

Leishmania are parasitic protozoa responsible for a broad spectrum of diseases affecting different mammals including human. During its lifecycle, the parasite alternates between two stages: one extra-cellular in the digestive tract of the sand fly vector and the other one obligate intracellular in macrophages of the mammalian host. Thus, a rapid adjustment to radically different environments is required for the survival of the parasite. The genomes of these parasites are organized in 36 chromosomes for the Old World species (L. donovani, L. infantum, L. major, L. tropica, $L$. aethiopica) [1] and 34 and 35 for the New World L. mexicana and L. braziliensis respectively [2]. Regarding the ploidy of Leishmania, different sets of data have suggested that Leishmania are aneuploid rather than strictly diploid [3-9]. Moreover, we have previously shown that Leishmania major genome exhibits an unusual feature termed 'mosaic aneuploidy' [3]: the population of cells within a strain, or even within a clone, is a mosaic, in that sense that the population is composed of mono-, di- and trisomic cells, in proportions that vary from one chromosome to another and from one strain to another. Taken together, these results strongly suggest that aneuploidy and mosaicism are constitutive features of L. major.

The aim of this work was to determine if these features were also present in other species of Leishmania. For this purpose, using fluorescence in situ hybridization (FISH), we analyzed the ploidy of individual cells in three Old World species (L. infantum, L. donovani and L. tropica) and one of the New World species (L. amazonensis) for six different chromosomes. Our data establish mosaic aneuploidy as a general constitutive feature of Leishmania. The consequences of mosaic aneuploidy upon the parasite's biology will be discussed, with respect to gene dosage, the absence of apparent detrimental effect of aneuploidy, and genetic exchange, in particular as an alternative to overcome the probable lack of gametes/meiosis. 


\section{Materials and methods}

\subsection{Parasites and in vitro cultivation}

Four strains of different species of Leishmania were analyzed: L. infantum (MHOM/FR/95/LEM3049), L. donovani (MHOM/IN/2003/LEM4537), L. tropica (MHOM/SY/92/LEM2514) and L. amazonensis (MHOM/GF/95/LEM3013). Strains were provided by the Biological Resource Centre of Leishmania (CRB-Leishmania) located in Montpellier ( $\quad$ http://www.parasitologie.univ-montp1.fr/english_vers/en_cryobanque.htm). Leishmania promastigotes were grown as described elsewhere, with the difference that supplemented RPMI1640 was replaced with supplemented SDM medium [10]. Parasites were maintained in log phase by splitting the culture every second day. Then, for FISH analysis, in order to minimize the number of dividing cells in the population, they were grown to late log phase and harvested. L. amazonensis MHOM/BR/1987/BA276 (BA276) promastigotes (kind gift of Aldina Barral and Manoel Barral-Netto, Fiocruz, Salvador de Bahia, Brazil) were grown in supplemented RPMI1640 [11].

\subsection{DNA probes}

For L. donovani, L. infantum and L. tropica, chromosome-specific probes (chromosomes 1, 2, 5, 22, 27, 29) were in large part similar to those used in Sterkers et al. 2010 [3]. The spliced leader RNA gene probe, specific for chromosome 2, was early gift from S.M. Beverley (Washington University School of Medicine, St. Louis). Specific probes for chromosomes 1, 5, 22, 27 were cosmid (L549) and BAC (LB00822, LB00273, LB00646) clones, respectively, that were kindly provided by Peter Myler (Seattle Biomedical Research Institute, USA) and Christiane HertzFowler and David Harris (Sanger Centre, Hinxton, UK). We also designed a chromosome 29specific PCR probe. Two successive ORFs (LmjF.29.0110 and LmjF.29.0120) were PCR- 
amplified separately from LmjF genomic DNA. PCR products were gel-purified and mixed at equimolar ratios. For L. amazonensis, chromosome-specific probes were constructed as follow : a genomic L. amazonensis MHOM/BR/1987/BA276 DNA cosmid library was constructed with the pcosTL vector (kind gift of Dr J. Kelly) as described [12] and propagated in the E. coli strain STBL-2 ${ }^{\mathrm{TM}}$ (Invitrogen) ; it contained about 20000 independent $50 \mathrm{~kb}$ insert clones, representing more than 15 haploid genome copies. Two thousand and five hundred individual clones were kept at $-80^{\circ} \mathrm{C}$ in 96 wells microtiter plates in $50 \%$ glycerol. Six independent clones (T3, T5, T7.2, T9; T15 and T18) were used in this study. The DNA from BAC and cosmid clones was prepared using Qiagen Large-Construct Kit.

\subsection{Pulse field gel electrophoresis and Southern blot}

The chromosomal specificity of the probes was assessed (i) by end-sequencing of the cosmid insert and sequence alignment (see Sterkers et al. 2011 [3] and Table S2); and (ii) by Southern blot analysis of the molecular karyotype of each strain. The molecular karyotypes of all the strains studied here were resolved by pulsed field gel electrophoresis (PFGE). Briefly, chromosomal DNA agarose blocks were prepared and processed for PFGE as described elsewhere [13]). PFGE was performed at $15^{\circ} \mathrm{C}$ in $1.5 \%$ agarose gels with $0.5 \times$ Tris-Borate-EDTA $(\mathrm{pH} 7.4)$ running buffer on home-made devices [13]). The electrophoretic conditions were the following: pulse/migration times of $300 \mathrm{~s} / 24 \mathrm{~h}, 130 \mathrm{~s} / 24 \mathrm{~h}$ and $90 \mathrm{~s} / 24 \mathrm{~h}$ with $7.5 \mathrm{~V} / \mathrm{cm}$. After migration, gels were stained with ethidium bromide and blotted by alkaline transfer onto nylon filters (Hybond $\mathrm{N}+$, Amersham). For Southern blot analysis, probes were labeled and hybridized with the DIG-High Prime DNA Labeling and Detection Starter Kit II according to the manufacturer's procedures (Roche Applied Sciences). 


\subsection{Fluorescence in situ hybridization, microscopy and fluorescence imaging}

For each Leishmania strain, the preparation of cells for immunofluorescence slides and the hybridization protocol used were as previously described [3]. All probes were labeled with tetramethyl-rhodamine-5-dUTP (Roche Applied Sciences) by using the Nick Translation Mix (Roche Applied Sciences) according to the manufacturer's instructions. Slides were then mounted in Vectashield (Vector Laboratories) with DAPI and microscopically examined [3, 14, 15]. Leishmania cells were viewed by bright field, and fluorescence was visualized using appropriate filters on a Zeiss Axioplan 2 microscope with a 100x objective. Digital images were captured using a Photometrics CoolSnap CDD camera (Roper Scientific) and processed with MetaView

(Universal Imaging). Z-Stack image acquisitions (15-25 planes of $0.25 \mathrm{~mm}$ ) were systematically performed for each cell analyzed using a Piezo controller, allowing to view the nucleus in all planes and to count the total number of labeled chromosomes. L. major reference strain 'Friedlin' (MHOM/IL/81/Friedlin) was used as positive control in all experiments (not shown).

\subsection{Data analysis}

Examination of the bright field and DAPI acquisitions allowed identifying the cells to be counted; mitotic cells were excluded from the analysis. Examination, plane by plane, of a numerically magnified view of each cell allowed the determination of the number of labeled chromosomes per individual cell. Each chromosome was then defined as mono-, di-, tri- or tetrasomic in the cell analyzed, and the ploidy/aneuploidy of the chromosome in the strain expressed as proportions.

\section{Results}

Eleven heterologous chromosomes (Chr.) were analyzed by FISH: Chr. 1, 2, 5, 22, 27 and 29 in three Leishmania strains of the Old World, L. infantum, L. donovani and L. tropica; and Chr. 14, 
16, 17, 23, 26 and 29 in one New World strain (L. amazonensis). The number of homologous chromosomes per individual interphasic cell was determined in all these strains.

\subsection{Probe efficiency and specificity}

Most probes designed for studying L. major by FISH [3] were used here with good efficiency in the three Old World species. As regards L. amazonensis, new species-specific probes were needed as the probes derived from $L$. major exhibited a too low specificity and sensitivity (not shown). Southern blotting of PFGE gels confirmed chromosome specificity in all cases (Fig. S1 and S2).

\subsection{FISH analysis}

Individual cell analysis showed variable 'somies' for all the chromosomes examined, i.e. the population is composed of mono-, di- and trisomic, and less frequently tetrasomic, cells, in proportions that vary depending on the chromosome and on the strain/species examined. For all species, each chromosome was observed in at least two ploidy states in the strain cell population (Fig. 1A-D). A rather diploid pattern was displayed in L. infantum, L. tropica and L. amazonensis strains, as five and four out of the six studied chromosomes for L. infantum and L. tropica and for L. amazonensis, respectively, were predominantly disomic. The chromosome ploidy of the L. donovani strain was more heterogeneous: two chromosomes were predominantly trisomic, two monosomic and one disomic. Interestingly, only one chromosome, chr. 2, exhibited a similar ploidy pattern in $L$. major ([3]), L. infantum, $L$. donovani and $L$. tropica (these data) strains, with a proportion of about $50 \%$ monosomic and $40 \%$ disomic. We could not study this chromosome in $L$. amazonensis, since we could not produce any chromosome 2-specific probe for this species; the spliced leader RNA gene probe located on chromosome 2 used for other species showed poor efficiency here. 
Similarly to that obtained from high throughput sequencing [4], we calculated a 'cumulative ploidy' per chromosome from FISH data in individual cells (Table S1). This varied from 1.6 to 2.8 (mean 2.2) depending on the chromosome and the Leishmania strain.

All in all, as all chromosomal contents varied among cells, we inferred that the five Leishmania species analyzed display a mosaic structure.

\section{Discussion}

Euploidy, mostly haploidy or diploidy, is the common rule in Eukaryotes and the alternation between these two states characterizes sexuality and genetic exchange between individuals. Aneuploidy has most often been associated with disease, lethality or malformation; one exception is a recent natural allopolyploid species, Tragopogon miscellus (Asteraceae), which shows extensive chromosomal variation, with $69 \%$ of the individuals aneuploid for one or more chromosomes [16]. Here, using FISH analysis, we show that the divergent eukaryote Leishmania constitutively displays mosaic aneuploidy across different species, this feature having been observed in four species of the Old and New World, in addition to L. major [3]. This has been shown for 11 different chromosomes in total. Data obtained from high throughput sequencing studies [4] further support mosaic aneuploidy as a general feature that affects all heterologous chromosomes of Leishmania.

Leishmania includes a large number of species which are responsible for a wide spectrum of human or animal diseases (cutaneous, mucosal and visceral forms). Paradoxically, the genome sequencing of these species showed a strong homogeneity in the genome organization, with an extreme degree of synteny observed among species and a remarkably low number of speciesspecific genes [4, 17]. In addition, Leishmania, like other Trypanosomatids, displays several unusual biological features for eukaryotes, among which a unique structural organization of the 
genome: indeed, genes are organized in large polycistronic transcription units made of functionally unrelated genes, and for which there is no promoter for RNA polymerase II. The resulting weak level of transcription regulation of protein-coding genes [18] may explain the tolerance to aneuploidy observed in Leishmania. Indeed, the changes in gene dosage induced by mosaic aneuploidy seem to have no detrimental effect on cell growth of Leishmania promastigotes in vitro. However, such a tolerance cannot explain the emergence of aneuploidy in Leishmania, since T. brucei has the same gene expression regulation system and yet remained diploid [3, 14]. Moreover, one cannot affirm that these parasites are insensitive to gene dosage variations; indeed, (i) several studies have shown that specific gene amplifications are correlated to drug resistance [19-22]; (ii) transcriptome studies do not allow correlating transcript levels to ploidy variations at the cell level, hence we cannot rule out that gene dosage variations do modulate transcript levels in individual cells.

Mosaic aneuploidy appears to be a major feature of the Leishmania genus which has numerous consequences on its genetics, hence on its biology. One of these consequences is that population genetics studies on this parasite need to be revisited. In particular, microsatellite data have to be analyzed in the light of aneuploidy of Leishmania. In our view, the conclusion that microsatellite data support diploidy rather than aneuploidy [23] is not justified. Indeed, PCR amplification of a given locus reveals either one or two bands that correspond to a phenotype and not a genotype. This, for example when applied to microsatellites, does not allow determining the number of allele (hence chromosome copies) present in the genome. As previously described in Leishmania, constitutive mosaic aneuploidy results from the over-replication of one homologue and/or underreplication events [24]. Over-replication of one homologue generates two identical alleles and those will be undistinguishable by PCR amplification. 
We already described another consequence of mosaic aneuploidy, which is that the cell population is essentially made of homozygous cells, yet retaining the global genetic heterogeneity of the strain [24]. As regards the heterozygote deficit in Leishmania 'populations', two events further contribute to the homozygosity of the strains : automixy [25] and selective pressures. These consequences are increased in low endemicity areas where reduced chances of encounters of different genotypes obviously make automixy predominant, as opposed to the formation of hybrids.

A more speculative issue may be addressed from our data. In most eukaryotes, the alternation of haploid/diploid stages, associated with gene shuffle and fusion of the gametes, is a hallmark of sexual reproduction. In Leishmania, genetic exchange during cyclical development in the sand fly vector has been experimentally demonstrated and is now believed to be a normal (although non obligatory) aspect of the parasite's biology [26, 27]; yet, the existence of meiosis remains unclear in Leishmania. As stated by Akopyants et al. [26], two hypotheses may explain this genetic exchange: either a fusion of parental cells which would be followed with a progressive chromosome number reduction [16] as seen in Candida albicans [28]; or a passage through gametic cells, i.e. classical meiosis. Indeed, the fusion of parental cells cannot be distinguished from the fusion of gametic cells during a meiotic process with the methods used hitherto. Fusion of in vitro grown promastigotes have previously been recorded [29]. Inbar et al. [27]. found chromosomal inheritance of both parental alleles at multiple unlinked loci, which they assume supports the existence of a meiotic process; they also stated the presence of so-called 'meiotic genes' which are known to be expressed in T. brucei [30] and exist in the Leishmania genome, such as DMC1 (Tb09.211.1210), HOP1 (Tb10.70.1530), MND1 (Tb11.02.3380) and SPO11 (Tb927.5.3760). However, as shown previously in C. albicans [28], the expression of meiosisspecific genes is not necessarily associated with meiosis. Moreover deletion of SPO11 prevented genetic recombination between homologous chromosomes during the $C$. albicans parasexual cycle 
[28]. Actually, as underlined by others [31], aneuploidy excludes classical meiosis and is compatible only with parasexual processes. In sexual reproduction, the genotypes of each given individual are stable/fixed for at least one generation. On the contrary, the mosaic aneuploidy system allows maintaining a dynamic genotypic diversity, with multiple possible genetic combinations [24] within the same cell population, which theoretically avoids the need for gametes, while still maintaining the adaptive potential of the parasite.

In total, mosaic aneuploidy, first described in only one species of Leishmania (L. major), now appears as a constitutive feature across the genus of this protozoon. This phenomenon has multiple and major consequences upon the biology of this parasite, which remain essentially unexplored. It constitutes one more example of the highly unusual biological features of this organism that challenge models derived from classical model organisms and often adopted as dogma in life sciences.

\section{Acknowledgments}

We wish to thank Peter Myler (Seattle Biomedical Research Institute, USA) as well as Christiane Hertz-Fowler and David Harris (Sanger Centre, Hinxton, Cambridge, UK) for providing BAC and cosmid clones, and Al Ivens (Sanger Centre, Hinxton, Cambridge, UK) for chromosomal mapping data. We also thank Stephen M. Beverley (Washington University School of Medicine, St. Louis, USA) for the gift of a plasmid containing the spliced leader RNA gene and John Kelly for that of the pcosTL plasmid vector. We are indebted with Aldina Barral and Manoel Barral-Netto (Fiocruz, Salvador de Bahia, Brazil) for giving us L. amazonensis MHOM/BR/1987/BA276. Finally, we gratefully acknowledge the expert advice and assistance of Julien Cau (RIO Imaging Platform in Montpellier) and Laurence Berry (University Montpellier 2/CNRS, UMR 5539) for fluorescence microscopy. 


\section{Reference}

[1] Wincker P, Ravel C, Blaineau C, Pages M, Jauffret Y, Dedet JP, Bastien P, The Leishmania genome comprises 36 chromosomes conserved across widely divergent human pathogenic species, Nucleic Acids Res 24 (1996) 1688-1694.

[2] Britto C, Ravel C, Bastien P, Blaineau C, Pages M, Dedet JP, Wincker P, Conserved linkage groups associated with large-scale chromosomal rearrangements between Old World and New World Leishmania genomes, Gene 222 (1998) 107-117.

[3] Sterkers Y, Lachaud L, Crobu L, Bastien P, Pagès M, FISH analysis reveals aneuploidy and continual generation of chromosomal mosaicism in Leishmania major, Cell Microbiol 13 (2011) 274-283.

[4] Rogers MB, Hilley JD, Dickens NJ, Wilkes J, Bates PA, Depledge DP, Harris D, Her Y, Herzyk P, Imamura H, Otto TD, Sanders M, Seeger K, Dujardin JC, Berriman M, Smith DF, Hertz-Fowler C, Mottram JC, Chromosome and gene copy number variation allow major structural change between species and strains of Leishmania, Genome Res, 2011.

[5] Cruz AK, Titus R, Beverley SM, Plasticity in chromosome number and testing of essential genes in Leishmania by targeting, Proc Natl Acad Sci U S A 90 (1993) 15991603.

[6] Ravel C, Dubessay P, Bastien P, Blackwell JM, Ivens AC, The complete chromosomal organization of the reference strain of the Leishmania Genome Project, $L$. major;Friedlin', Parasitol Today 14 (1998) 301-303.

[7] Sunkin SM, Kiser P, Myler PJ, Stuart K, The size difference between Leishmania major friedlin chromosome one homologues is localized to sub-telomeric repeats at one chromosomal end, Mol Biochem Parasitol 109 (2000) 1-15. 
[8] Dubessay P, Ravel C, Bastien P, Stuart K, Dedet JP, Blaineau C, Pages M, Mitotic stability of a coding DNA sequence-free version of Leishmania major chromosome 1 generated by targeted chromosome fragmentation, Gene 289 (2002) 151-159.

[9] Martinez-Calvillo S, Stuart K, Myler PJ, Ploidy changes associated with disruption of two adjacent genes on Leishmania major chromosome 1, Int J Parasitol 35 (2005) 419429.

[10] Dubessay $P$, Blaineau $C$, Bastien $P$, Pages $M$, Chromosome fragmentation in Leishmania, Methods Mol Biol 270 (2004) 353-378.

[11] Lodes MJ, Merlin G, deVos T, Ghosh A, Madhubala R, Myler PJ, Stuart K, Increased expression of LD1 genes transcribed by RNA polymerase I in Leishmania donovani as a result of duplication into the rRNA gene locus, Mol Cell Biol 15 (1995) 6845-6853.

[12] Kelly JM, Das $P$, Tomas AM, An approach to functional complementation by introduction of large DNA fragments into Trypanosoma cruzi and Leishmania donovani using a cosmid shuttle vector, Molecular and Biochemical Parasitology 65 (1994) 51-62.

[13] Blaineau C, Bastien P, Rioux JA, Roizes G, Pages M, Long-range restriction maps of size-variable homologous chromosomes in Leishmania infantum, Mol Biochem Parasitol 46 (1991) 292-302.

[14] Ersfeld K, Gull K, Partitioning of large and minichromosomes in Trypanosoma brucei, Science 276 (1997) 611-614.

[15] Freitas-Junior LH, Bottius E, Pirrit LA, Deitsch KW, Scheidig C, Guinet F, Nehrbass $\mathrm{U}$, Wellems TE, Scherf A, Frequent ectopic recombination of virulence factor genes in telomeric chromosome clusters of $P$. falciparum, Nature 407 (2000) 1018-1022.

[16] Chester M, Gallagher JP, Symonds VV, Cruz da Silva AV, Mavrodiev EV, Leitch $A R$, Soltis PS, Soltis DE, Extensive chromosomal variation in a recently formed natural 
allopolyploid species, Tragopogon miscellus (Asteraceae), Proc Natl Acad Sci U S A (2012).

[17] Raymond F, Boisvert S, Roy G, Ritt JF, Legare D, Isnard A, Stanke M, Olivier M, Tremblay MJ, Papadopoulou B, Ouellette M, Corbeil J, Genome sequencing of the lizard parasite Leishmania tarentolae reveals loss of genes associated to the intracellular stage of human pathogenic species, Nucleic Acids Res 40 (2012) 1131-1147.

[18] Clayton CE, Life without transcriptional control? From fly to man and back again, EMBO J 21 (2002) 1881-1888.

[19] Beverley SM, Gene amplification in Leishmania, Annu Rev Microbiol 45 (1991) 417-444.

[20] Segovia M, Leishmania gene amplification: a mechanism of drug resistance, Ann Trop Med Parasitol 88 (1994) 123-130.

[21] Downing T, Imamura H, Decuypere S, Clark TG, Coombs GH, Cotton JA, Hilley JD, de Doncker S, Maes I, Mottram JC, Quail MA, Rijal S, Sanders M, Schonian G, Stark O, Sundar S, Vanaerschot M, Hertz-Fowler C, Dujardin JC, Berriman M, Whole genome sequencing of multiple Leishmania donovani clinical isolates provides insights into population structure and mechanisms of drug resistance, Genome Res 21 (2011) 21432156.

[22] Ubeda JM, Legare D, Raymond F, Ouameur AA, Boisvert S, Rigault P, Corbeil J, Tremblay MJ, Olivier M, Papadopoulou B, Ouellette M, Modulation of gene expression in drug resistant Leishmania is associated with gene amplification, gene deletion and chromosome aneuploidy, Genome Biol 9 (2008) R115.

[23] Rougeron V, De Meeus T, Hide M, Waleckx E, Bermudez H, Arevalo J, LlanosCuentas A, Dujardin JC, De Doncker S, Le Ray D, Ayala FJ, Banuls AL, Extreme inbreeding in Leishmania braziliensis, Proc Natl Acad Sci U S A 106 (2009) 10224-10229. 
[24] Sterkers Y, Lachaud L, Bourgeois N, Crobu L, Bastien P, Pages M, Novel insights into genome plasticity in Eukaryotes: mosaic aneuploidy in Leishmania, Mol Microbiol (2012).

[25] Bastien P, Blaineau C, Pages M, Leishmania: sex, lies and karyotype, Parasitol Today 8 (1992) 174-177.

[26] Akopyants NS, Kimblin N, Secundino N, Patrick R, Peters N, Lawyer P, Dobson DE, Beverley SM, Sacks DL, Demonstration of genetic exchange during cyclical development of Leishmania in the sand fly vector, Science 324 (2009) 265-268.

[27] Inbar E, Akopyants NS, Charmoy M, Romano A, Lawyer P, Elnaiem DE, Kauffmann F, Barhoumi M, Grigg M, Owens K, Fay M, Dobson DE, Shaik J, Beverley SM, Sacks D, The Mating Competence of Geographically Diverse Leishmania major Strains in Their Natural and Unnatural Sand Fly Vectors, PLoS Genet 9 (2013) e1003672.

[28] Forche A, Alby K, Schaefer D, Johnson AD, Berman J, Bennett RJ, The parasexual cycle in Candida albicans provides an alternative pathway to meiosis for the formation of recombinant strains, PLoS Biol 6 (2008) e110.

[29] Lanotte G, Rioux JA, Cell fusion in Leishmania (Kinetoplastida, Trypanosomatidae), C R Acad Sci III 310 (1990) 285-288.

[30] Peacock L, Ferris V, Sharma R, Sunter J, Bailey M, Carrington M, Gibson W, Identification of the meiotic life cycle stage of Trypanosoma brucei in the tsetse fly, Proc Natl Acad Sci U S A 108 (2011) 3671-3676.

[31] Mannaert A, Downing T, Imamura H, Dujardin JC, Adaptive mechanisms in pathogens: universal aneuploidy in Leishmania, Trends Parasitol 28 (2012) 370-376. 
A- L. infantum

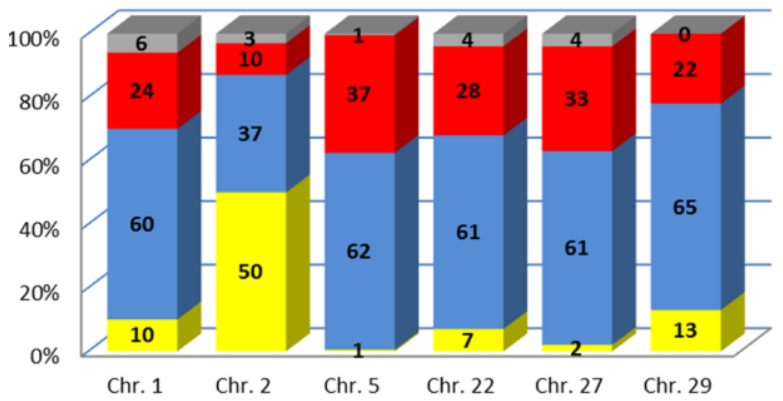

C- L. tropica

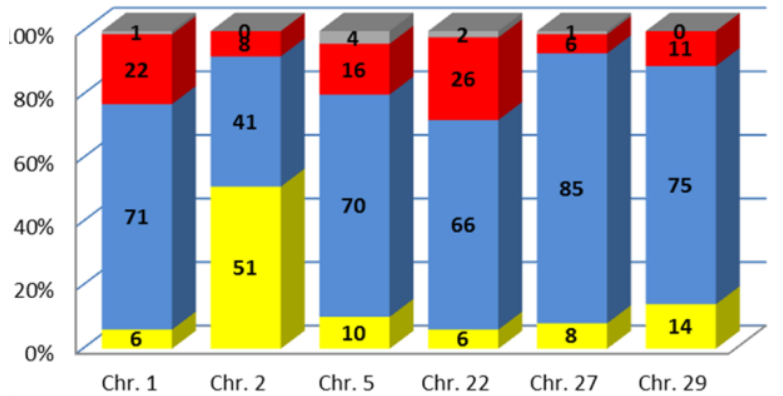

B- L. donovani

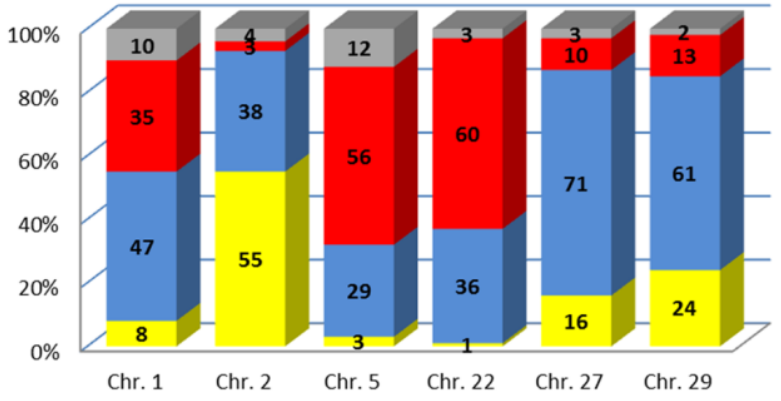

D- L. amazonensis

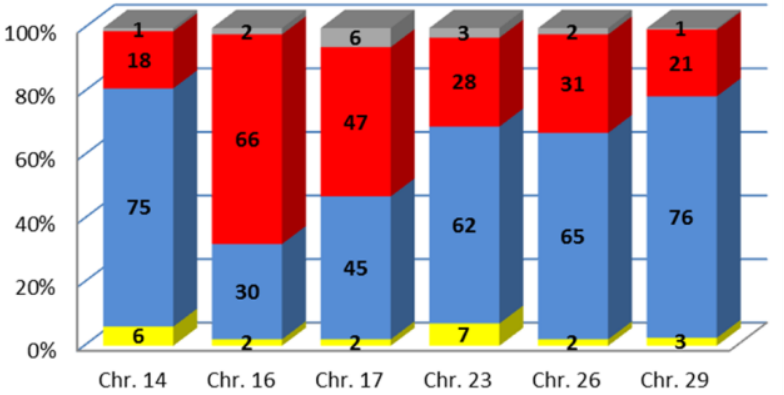

Figure 1. Mosaic aneuploidy in four Leishmania species of the Old and New World

Histograms show the proportions (percentages in ordinate) of mono- (yellow), di- (blue), tri- (red) and tetrasomic (grey) chromosomes in the different Leishmania species studied: A- L. infantum (MHOM/FR/95/LEM3049), B- L. donovani (MHOM/IN/2003/LEM4537), C- L. tropica (MHOM/SY/92/LEM2514) and D- L. amazonensis (MHOM/GF/95/LEM3013). Each bar represents one of the six chromosomes studied (abscissa). The ploidy of each chromosome was calculated from the examination of 3D views of a mean of 244 labeled cells for each probe and strain; a total of 5846 cells were examined. Mosaicism was observed for all the chromosomes analyzed; nevertheless, the proportions of mono-, di- , tri- or tetrasomic chromosomes vary depending on the chromosome and on the strain examined. 


\section{Supporting information}

Table S1. Percentages of nulli-, mono-, di-, tri-, and tetrasomic cells observed for six chromosomes in in four Leishmania species of the Old and New World (raw data).

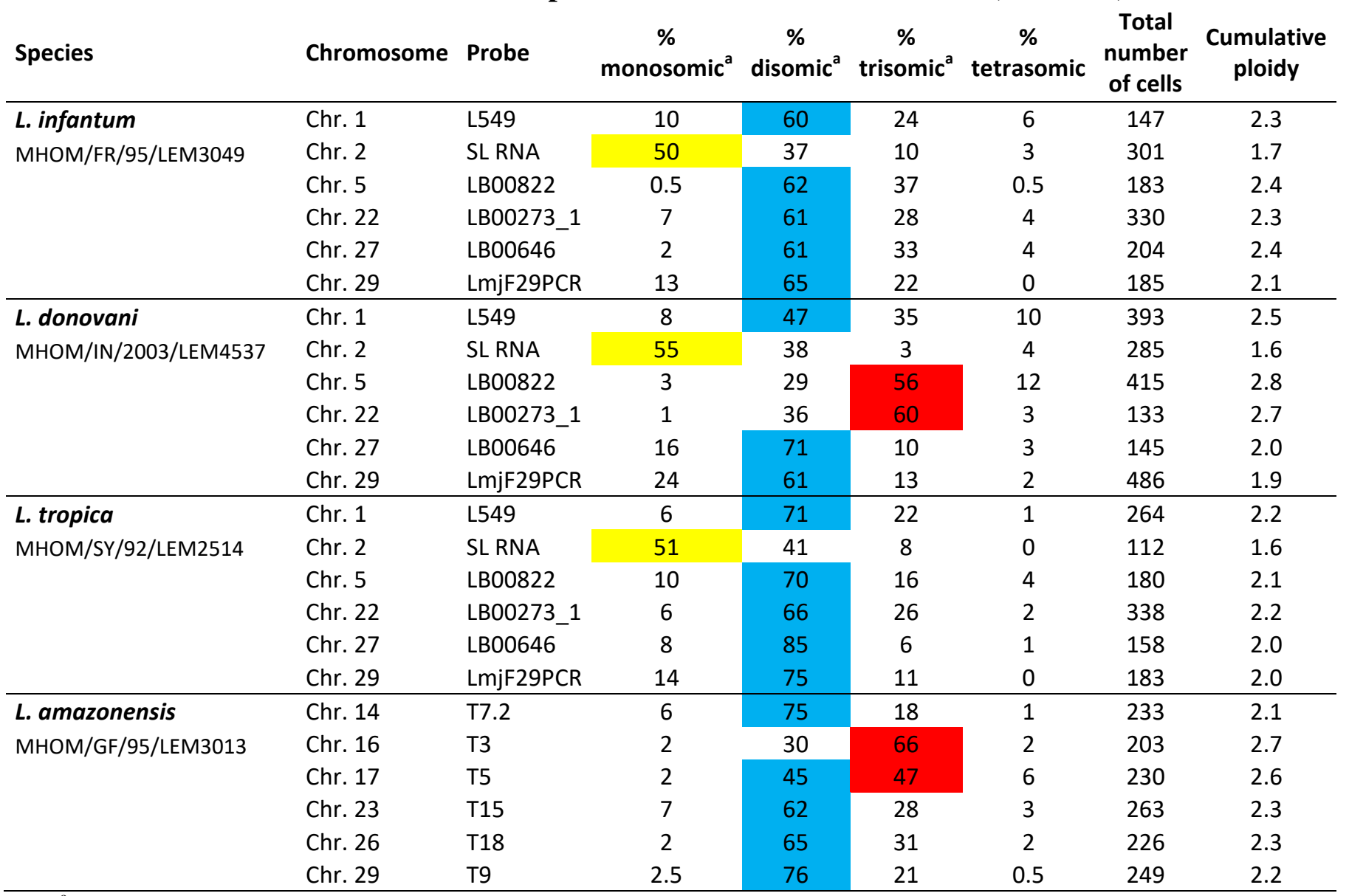

\footnotetext{
${ }^{\mathrm{a}}$ The predominant ploidy is indicated by a colored box (same color code as Fig. 1).
} 
Table S2. Genomic localization of the DNA cosmids used to determine the ploidy of L. amazonensis

\begin{tabular}{|c|c|c|c|c|c|c|c|c|c|c|c|}
\hline Chromosome & $\begin{array}{c}\text { Cosmid } \\
\text { code } \\
\text { name }\end{array}$ & Primer $^{\mathrm{a}}$ & Sequence ID ${ }^{a}$ & Identities $^{c}$ & Gaps $^{c}$ & $\begin{array}{l}\text { Query } \\
\text { start }^{c}\end{array}$ & $\begin{array}{l}\text { Query } \\
\text { end }^{c}\end{array}$ & $\begin{array}{l}\text { Subject } \\
\text { start }^{c}\end{array}$ & $\begin{array}{c}\text { Subject } \\
\text { end }^{c}\end{array}$ & Score ${ }^{c}$ & $\mathbf{P}^{c}$ \\
\hline Chr. 14 & $\mathrm{T7.2}$ & T3 & emb|FR799567.1| & $\begin{array}{c}977 / 1003 \\
(97 \%)\end{array}$ & $\begin{array}{c}13 / 1003 \\
(1 \%)\end{array}$ & 14 & 1009 & 233213 & 232217 & $\begin{array}{c}1701 \text { bits } \\
(921)\end{array}$ & 0.0 \\
\hline Chr. 14 & $\mathrm{T7.2}$ & G071 & emb|FR799567.1| & $\begin{array}{c}851 / 863 \\
(99 \%)\end{array}$ & $\begin{array}{c}3 / 863 \\
(0 \%) \\
\end{array}$ & 1 & 860 & 193609 & 194471 & $\begin{array}{c}1526 \text { bits } \\
(826)\end{array}$ & 0.0 \\
\hline Chr. 16 & T3 & T3 & emb|FR799569.1| & $\begin{array}{c}383 / 406 \\
(94 \%)\end{array}$ & $\begin{array}{c}5 / 406 \\
(1 \%)\end{array}$ & 2 & 406 & 514159 & 513758 & $\begin{array}{c}628 \text { bits } \\
(340)\end{array}$ & $8,00 E-177$ \\
\hline Chr. 16 & T3 & G071 & emb|FR799569.1| & $\begin{array}{c}387 / 395 \\
(98 \%)\end{array}$ & $\begin{array}{c}3 / 395 \\
(1 \%) \\
\end{array}$ & 1 & 392 & 474159 & 474553 & $\begin{array}{c}686 \text { bits } \\
(371)\end{array}$ & 0.0 \\
\hline Chr. 17 & T5 & T3 & emb|FR799570.1| & $\begin{array}{c}663 / 668 \\
(99 \%)\end{array}$ & $\begin{array}{c}0 / 668 \\
(0 \%)\end{array}$ & 7 & 674 & 397498 & 398165 & $\begin{array}{c}1206 \text { bits } \\
(653)\end{array}$ & 0.0 \\
\hline Chr. 17 & T5 & G071 & emb|FR799570.1| & $\begin{array}{c}593 / 605 \\
(98 \%) \\
\end{array}$ & $\begin{array}{c}0 / 605 \\
(0 \%) \\
\end{array}$ & 1 & 605 & 435914 & 435310 & $\begin{array}{c}1059 \text { bits } \\
(573)\end{array}$ & 0.0 \\
\hline Chr. 23 & T15 & T3 & emb|FR799576.1| & $\begin{array}{c}801 / 844 \\
(95 \%)\end{array}$ & $\begin{array}{c}24 / 844 \\
(3 \%)\end{array}$ & 1 & 824 & 94697 & 95536 & $\begin{array}{c}1299 \text { bits } \\
(703)\end{array}$ & 0.0 \\
\hline Chr. 23 & T15 & G071 & emb|FR799576.1| & $\begin{array}{c}858 / 887 \\
(97 \%) \\
\end{array}$ & $\begin{array}{c}8 / 887 \\
(1 \%) \\
\end{array}$ & 12 & 898 & 130562 & 129684 & $\begin{array}{c}1480 \text { bits } \\
(801)\end{array}$ & 0.0 \\
\hline Chr. 26 & T18 & T3 & emb|FR799579.1| & $\begin{array}{c}883 / 889 \\
(99 \%)\end{array}$ & $\begin{array}{c}1 / 889 \\
(0 \%)\end{array}$ & 22 & 910 & 882720 & 883607 & $\begin{array}{c}1613 \text { bits } \\
(873)\end{array}$ & 0.0 \\
\hline Chr. 26 & T18 & G071 & nd & nd & nd & nd & nd & nd & nd & nd & nd \\
\hline Chr. 29 & T9 & T3 & FR799582.1 & $\begin{array}{c}831 / 844 \\
(98 \%)\end{array}$ & $\begin{array}{c}0 / 844 \\
(0 \%)\end{array}$ & 29 & 872 & 530572 & 529729 & $\begin{array}{c}1500 \text { bits } \\
(812)\end{array}$ & 0.0 \\
\hline Chr. 29 & T9 & G071 & FR799582.1 & $\begin{array}{l}64 / 67 \\
(96 \%)\end{array}$ & $0 / 67$ (0\%) & 6 & 72 & 502416 & 502482 & $\begin{array}{c}113 \text { bits } \\
(61)\end{array}$ & $1,00 \mathrm{E}-22$ \\
\hline
\end{tabular}

${ }^{a}$ Cosmid end sequences were obtained using the universal primer T3 and primer G071 (5'-CTT CAG ATG CCT GGT TG-3'). ${ }^{b}$ BLAST analysis was performed in

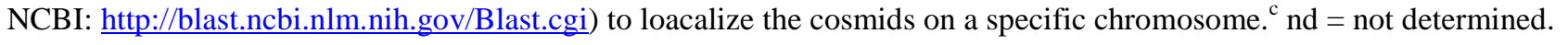



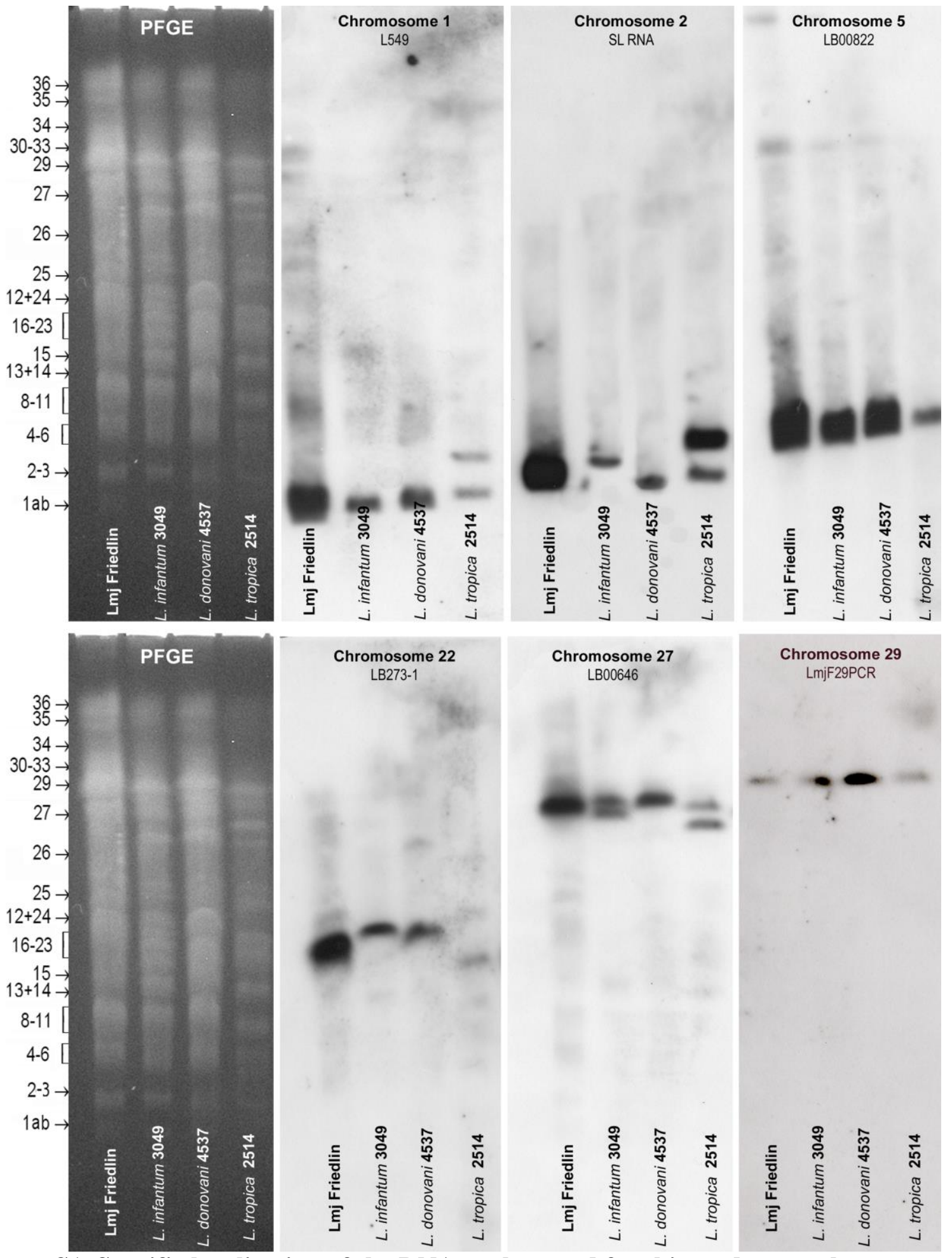

Figure S1. Specific localization of the DNA probes used for this study onto chromosomes of three Leishmania species of the Old World.

Molecular karyotypes of Leishmania infantum (MHOM/FR/95/LEM3049), L. donovani (MHOM/IN/2003/LEM4537), L. tropica (MHOM/SY/92/LEM2514) were resolved by PFGE and transferred on nylon membranes for Southern blot analysis. The position and number of the $36 \mathrm{LmjF}$ chromosomes are shown on the left of each molecular karyotype (Ravel et al., Parasitol Today 1998). Each probe proved specific for a given chromosome, confirming end-sequence data (Sterkers et al. Cell Microbiol 2011). SL RNA = spliced leader RNA (or mini-exon). 


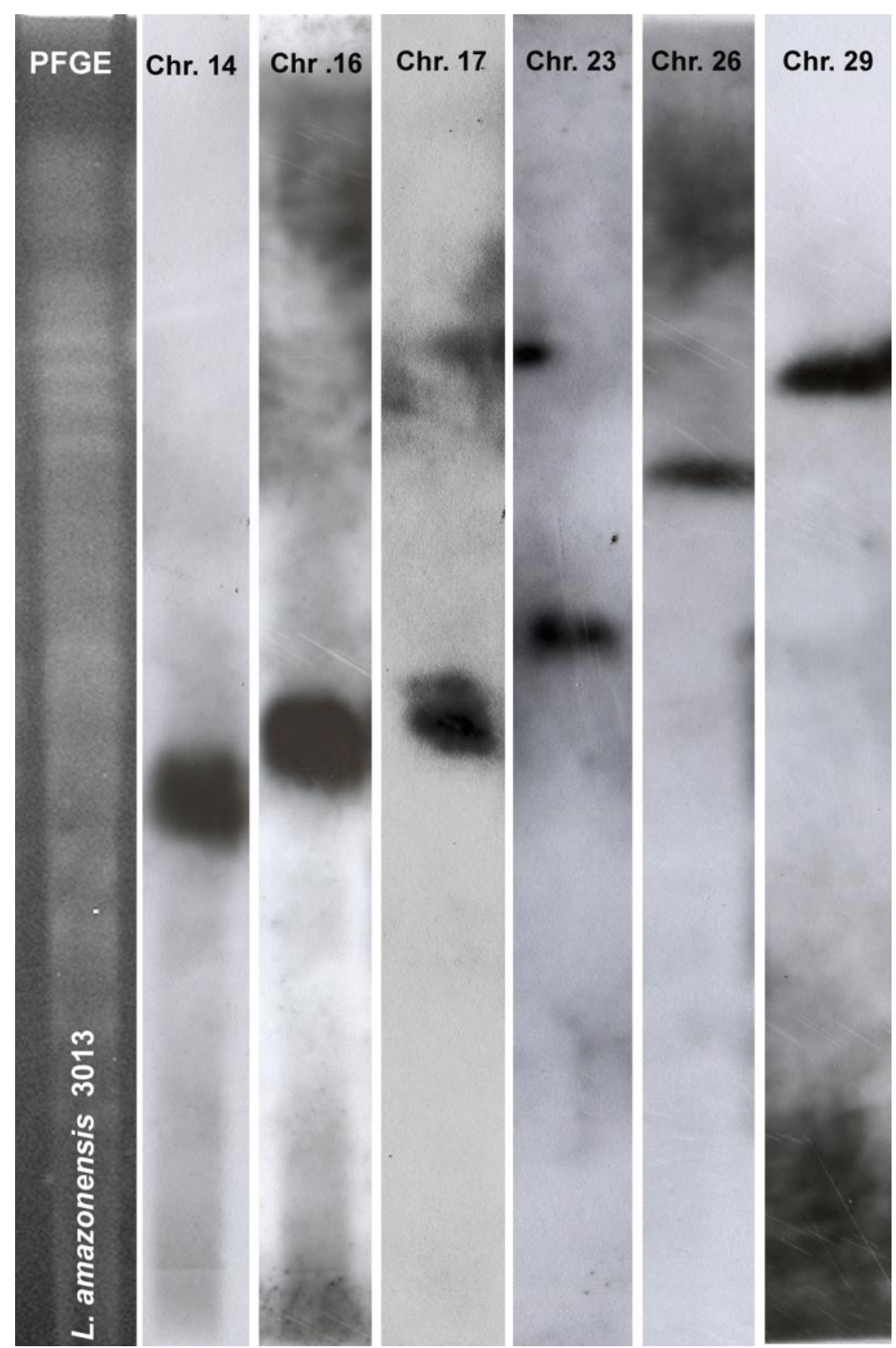

Figure S2. Specific localization of the DNA probes used for this study onto chromosomes of Leishmania amazonensis.

Unsheared chromosomal DNA was prepared form L. amazonensis (MHOM/GF/95/LEM3013) and separated by PFGE as described (Ravel et al., Parasitol Today 1998). The ethidium bromide-stained PFGE gel (molecular karyotype) is shown on the left and the autoradiograms of the specific probe hybridizations are shown on the right. Each probe proved specific for a given chromosome (Chr. 14, Chr. 16, Chr. 17, Chr. 23, Chr. 26 and Chr. 29), confirming end-sequence data (Table S2). 